\title{
Hereditary cancer risk assessment: essential tools for a better approach
}

\author{
Israel Gomy* and Maria Del Pilar Estevez Diz
}

\begin{abstract}
Hereditary cancer risk assessment (HCRA) is a multidisciplinary process of estimating probabilities of germline mutations in cancer susceptibility genes and assessing empiric risks of cancer, based on personal and family history. It includes genetic counseling, testing and management of at-risk individuals so that they can make well-informed choices about cancer surveillance, surgical treatment and chemopreventive measures, including biomolecular cancer therapies. Providing patients and family members with an appropriate HCRA will contribute to a better process of making decisions about their personal and family risks of cancer. Following individuals at high risk through screening protocols, reassuring those at low risk, and referring those at increased risk of hereditary cancer to a cancer genetics center may be the best suitable approach of HCRA.
\end{abstract}

Keywords: Germline, Susceptibility, Genetic testing, Hereditary cancer, Counseling

\section{Introduction}

Within the last decade, emerging biomolecular technologies, such as whole-exome and genome sequencing and high-throughput genotyping have been rapidly growing and enlightening the knowledge of inherited cancer susceptibility. Meanwhile, important issues on bench-to-bedside translation of these major breakthroughs into clinical practice have been equally addressed. Nevertheless, one essential component of these aspects includes the counseling of individuals with hereditary cancer risk. The increased public awareness of the genetic aspects of cancer susceptibility has resulted in more enquiries from clinical and surgical oncologists about which would be the best approach for their patients so that appropriate management could be provided.

More than fifty rare Mendelian cancer syndromes are caused by highly penetrant germline mutations affecting either tumor suppressor genes, DNA repair genes or proto-oncogenes, mostly with autosomal dominant inheritance (Table 1). Their cumulative relative risks are the highest ones (more than 10 times), dramatically affecting the quality of life and decreasing its expectancy. Moderately penetrant germline mutations are also rare,

\footnotetext{
* Correspondence: israel.gomy@icesp.org.br

Instituto do Câncer do Estado de São Paulo da Faculdade de Medicina da Universidade de São Paulo, Av. Dr. Arnaldo, 251, Cerqueira César, São Paulo, Brazil
}

\section{() Biomed Central}

although more prevalent in selected populations, and increase approximately two to five times the general population risk. Germline variants with low penetrance are relatively common in most populations, and have been identified through genome-wide association studies (GWAS). Although their size effects are individually low $(<1.5)$, they may be relevant on risk stratification. Actually, they explain part of the excess familial risk and the so-called 'missing heritability' remains largely unknown [1]. Nowadays, with the advance of next-generation sequencing and genotyping assays, more variants have been identified, shedding new light on the genomic architecture of the inherited susceptibility of cancer.

This review aims to describe a high-quality approach of delivering hereditary cancer risk assessment (HCRA) within a multidisciplinary context.

\section{Referrals for HCRA}

In addition to age, a positive family history of cancer is the single most important constitutional risk factor for which early recognition and intervention could be lifesaving.

Identifying the inherited risk factors of cancer in a given individual or family is complex and raises important psychological, social, and ethical issues. It requires the knowledge of genetics and oncology, besides suitable communication skills, demanding more time than from 
Table 1 Hereditary cancer syndromes

\begin{tabular}{|c|c|c|c|c|}
\hline Syndrome & Gene & $\begin{array}{l}\text { Mutation } \\
\text { status }\end{array}$ & Penetrance & Tumors \\
\hline \multirow[t]{5}{*}{ Hereditary breast and/or ovarian cancer } & $B R C A 1$ & Heterozygous & High & Breast cancer \\
\hline & $B R C A 2$ & & & Ovarian cancer \\
\hline & RAD51 $(B, C, D)$ & & intermediate & Pancreatic cancer \\
\hline & ATM & & intermediate & Prostate cancer \\
\hline & CHEK2 & & intermediate & Colorectal cancer \\
\hline \multirow[t]{5}{*}{ Lynch syndrome } & MLH1 & Heterozygous & High & Colorectal cancer \\
\hline & MSH2 & & & Endometrial cancer \\
\hline & MSH6 & & & Ovarian cancer \\
\hline & PMS2 & & & Gastric cancer \\
\hline & EPCAM & & & \\
\hline \multirow[t]{2}{*}{ MMR cancer syndrome } & MMR genes & Homozygous & High & Leukemia, lymphoma \\
\hline & & & & Rhabdomyosarcoma \\
\hline \multirow[t]{3}{*}{ Familial adenomatous polyposis } & $A P C$ & Heterozygous & High & $\begin{array}{l}\text { Gastrointestinal } \\
\text { adenomas }\end{array}$ \\
\hline & & & & Colorectal cancer \\
\hline & & & & Duodenal cancer \\
\hline MYH-associated polyposis & MUTYH & Homozygous & High & Colorectal cancer \\
\hline \multirow{2}{*}{$\begin{array}{l}\text { Polymerase proofreading-associated } \\
\text { polyposis }\end{array}$} & POLE & Heterozygous & High & Colorectal cancer \\
\hline & POLD1 & & & Endometrial cancer \\
\hline \multirow[t]{3}{*}{ Bloom syndrome } & BLM1 & Homozygous & High & Leukemia \\
\hline & & & & Colorectal cancer \\
\hline & & & & Wilms tumor \\
\hline \multirow[t]{3}{*}{ Nijmegen syndrome } & NBS1 & Homozygous & High & Lymphoma \\
\hline & & & & Medulloblastoma \\
\hline & & & & Rhabdomyosarcoma \\
\hline \multirow[t]{3}{*}{ Fanconi anemia } & FANC genes (includes BRCA2, PALB2, & Homozygous & High & Leukemia \\
\hline & $B R I P T$ & & & Medulloblastoma \\
\hline & & & & Wilms tumor \\
\hline Li-Fraumeni syndrome & TP53 & Heterozygous & High & Breast cancer \\
\hline \multirow[t]{3}{*}{ Li-Fraumeni like syndrome } & CHEK2 & & intermediate & Sarcoma \\
\hline & & & & Adrenocortical cancer \\
\hline & & & & Brain tumor \\
\hline \multirow[t]{5}{*}{ Cowden syndrome } & PTEN & Heterozygous & High & Hamartomatous polyps \\
\hline & & & & Skin tumors \\
\hline & & & & Breast cancer \\
\hline & & & & Thyroid cancer \\
\hline & & & & Endometrial cancer \\
\hline \multirow[t]{2}{*}{ Hereditary diffuse gastric cancer } & $\mathrm{CDH} 1$ & Heterozygous & High & Diffuse gastric cancer \\
\hline & & & & Lobular Breast cancer \\
\hline \multirow[t]{5}{*}{ Peutz-Jeghers syndrome } & STK11 & Heterozygous & High & Hamartomatous polyps \\
\hline & & & & Colorectal \\
\hline & & & & Small bowel \\
\hline & & & & Breast cancer \\
\hline & & & & Pancreatic cancer \\
\hline
\end{tabular}


Table 1 Hereditary cancer syndromes (Continued)

\begin{tabular}{|c|c|c|c|c|}
\hline \multirow[t]{3}{*}{ Juvenile polyposis } & SMAD4 & Heterozygous & High & Hamartomatous polyps \\
\hline & BMPR1A & & & Colorectal cancer \\
\hline & & & & Pancreatic cancer \\
\hline \multirow[t]{2}{*}{ Melanoma syndromes } & CDKN2A & Heterozygous & High & Malignant melanoma \\
\hline & CDK4 & & & Pancreatic cancer \\
\hline \multirow[t]{4}{*}{ Neurofibromatosis } & NF1 & Heterozygous & High & Vestibular schwannoma \\
\hline & NF2 & & & Meningioma \\
\hline & & & & Neurofibroma \\
\hline & & & & Optic glioma \\
\hline \multirow[t]{3}{*}{ Tuberous sclerosis } & TSC1 & Heterozygous & High & Renal angiomyolipoma \\
\hline & TSC2 & & & Subependimoma \\
\hline & & & & Giant cell astrocytoma \\
\hline \multirow[t]{3}{*}{ Von Hippel-Lindau syndrome } & $V H L$ & Heterozygous & High & Hemangioblastomas \\
\hline & & & & Renal cell cancer \\
\hline & & & & Pheochromocytoma \\
\hline Chuvash policitemia & & Homozygous & High & Vertebral angiomas \\
\hline \multirow[t]{2}{*}{ Birt-Hogg-Dubè syndrome } & FLCN & Heterozygous & High & Renal cell cancer \\
\hline & & & & Skin tumors \\
\hline \multirow[t]{2}{*}{ Papillary renal cancer syndromes } & $\mathrm{FH}$ & Heterozygous & High & Renal cell cancer \\
\hline & MET & & & \\
\hline Retinoblastoma & $R B 1$ & Heterozygous & High & Retinoblastoma \\
\hline \multirow[t]{2}{*}{ Hereditary Paraganglioma } & $S D H(A, B, C, D)$ & Heterozygous & High & Paraganglioma \\
\hline & & & & Pheochromocytoma \\
\hline Multiple Endocrine Neoplasia1 & MEN1 & Heterozygous & High & Pituitary adenoma \\
\hline \multirow[t]{3}{*}{ Multiple Endocrine Neoplasia2 } & RET & & & Parathyroid adenoma \\
\hline & & & & Medular thyroid cancer \\
\hline & & & & Pheochromocytoma \\
\hline
\end{tabular}

most clinical services. The American Society of Clinical Oncology (ASCO), the National Society of Genetic Counselors (NSGC), the Oncology Nursing Society (ONS), and other health care professional organizations have set forth guidelines outlining standards for the practice of cancer risk counseling, risk assessment, and genetic testing [2-4]. It also includes genetic testing as appropriate and management of at-risk individuals so that they can make informed choices about cancer screening, surgical and/or chemopreventive risk management options, as well as targeted cancer therapies [5]. In Table 2 there are possible indications of referral for HCRA.

\section{Components of the HCRA}

The genetic risk assessment of an individual with cancer is based upon the careful analysis of the personal history, detailed family history and physical examination when appropriate. It requires confirmation of the diagnosis in affected relatives, preferably through biopsies or, whenever possible, death certificates or autopsies.

These are some important issues to be addressed within the HCRA process [5]:

1. Family pedigrees drawings with at least three generations in both sides of family;

2. Patients and relatives:

a. Current age, age at diagnosis, age at death, primary site, pathologic features, treatments;

b. Ancestry (especially if Ashkenazi Jewish);

c. Previous surgeries, biopsies, diseases;

d. Endogenous risk factors: age at menarche, fertility history;

e. Exogenous risk factors: tobacco/alcohol use, food intake, hormones, exercises;

f. Cancer screening: mammography, gastrointestinal endoscopy, PSA;

g. Chemoprevention. 
Table 2 Possible indications of referrals for hereditary cancer risk assessment

Personal history
Early onset of cancer diagnosis (e.g. breast cancer < 45 years,
colorectal cancer < 50 years)
Multiple associated primary cancers: breast/ovary, colorectal/
endometrium
Male breast cancer
Ovarian, fallopian tube, primary peritoneal cancer
Breast cancer and thyroid, sarcoma, adrenocortical carcinoma
Multiple colon polyps (>10 cumulative)
Colorectal or endometrial cancer with microsattelite instability
and/or lack of expression of mismatch repair protein(s) by
immunohistochemistry

3. Physical examination (when appropriate): skin, head circumference, tongue, oral mucosa, thyroid, hands and feet, abdomen;

4. Psychosocial and family dynamic;

5. Basic principles of cancer genetics;

6. Differential diagnosis;

7. Mutation probabilities and empiric risks;

8. Pre-test genetic counseling:

a. Indentify the best individuals to test;

b. Prioritize order of testing (germline, tumor);

c. Explain test techniques, limitations, sensitivity/ specificity;

d. Facilitate informed consent: possible outcomes (positive, true-negative, uninformative), costs, turn-around-time, insurance coverage;

e. Address psychological, ethical, cultural, communication issues.

9. Post-test genetic counseling:

a. Disclosure and interpretation of results;

b. Address psychological and ethical concerns;

c. Identify at-risk family members;

d. Discuss communication of results to at-risk family members.

10.Personalized risk management strategies:

a. Screening/surveillance exams;

b. Risk reduction, cancer prevention (surgeries, chemoprevention);

c. Empiric strategies for uninformative results.

\section{Predicting germline mutations}

Several models are available to estimate the likelihood of detecting a mutation in a cancer-susceptibility gene and each model is utilized selectively based on the characteristics of the patient's personal and family history.

If a mutation in the BRCA gene is suspected to be present in a hereditary breast and ovarian cancer family, there are several models available to predict the probability of an individual

\section{Family history}

Three close relatives (same side) with cancer of the same or syndromically related type (breast/ovary, colorectal/endometrium)

Two close relatives (same side) with cancer of the same or related type with at least one affected under 50 years

One first-degree relative with early onset cancer (breast $<45$ years, colorectal $<50$ years)

One first-degree relative with multiple primary cancers

Two or more relatives with uncommon cancers (sarcoma, glioma, hemangioblastoma, etc.)

Relatives of patients with known BRCA, APC, MUTYH, mismatch repair mutations

Many relatives with cancer but no criteria for testing are fulfilled carrying such a mutation. These models include the Couch [6], Penn II [7], Myriad [8], BRCAPRO [9-11], Tyrer-Cuzick [12], and BOADICEA models [13]. Such models incorporate breast and ovarian cancer in first- and second-degree relatives, age of onset of cancer, Ashkenazi Jewish ancestry, and some are starting to incorporate other ethnic backgrounds.

There are similar models for predicting mutation in DNA mismatch repair (MMR) genes in suspected Lynch syndrome families, including Wijnen [14], MMRpro [15], MMRpredict [16], and PREMM1,2,6 [17]. However, in the HCRA of colon cancer families, it is more common to use established criteria as an indication for testing, including the Amsterdam I and II [18], or the revised Bethesda Guidelines [19], which determine eligibility for tumor analysis to detect microsatellite instability that would aid to guide genetic testing of the MMR genes.

Furthermore, there are established diagnostic criteria for Li-Fraumeni $[20,21]$ and Cowden syndromes [22,23], as well as mutation probability models for hereditary melanoma [24] and pancreatic cancer (Table 3).

The use of mutation predictability models is important for several reasons. First, calculating the likelihood of a germline mutation can help clinicians determine which family member is the best candidate for testing. Second, due to the high cost of genetic testing, numerical calculations of mutation probability may provide supportive evidence for insurance companies. Third, for psychosocial reasons, patients who are informed with a numerical estimation of a mutation may have more realistic expectations about the possibility of a positive result. Finally, for worried patients with a low probability of carrying a mutation, and for those with mutations without any influence in gene expression or stability, numerical presentations may provide substantial reassurance regarding screening guidelines based on empiric cancer risks. A recent study highlighted possible health benefits and the cost-effectiveness of primary 
Table 3 Clinical criteria guidelines and mutation probability models utilized for HCRA

\begin{tabular}{|c|c|c|c|}
\hline Syndrome & Model & Genes included* & Clinical criteria/tumors included* \\
\hline \multirow{6}{*}{$\begin{array}{l}\text { Hereditary breast and } \\
\text { ovarian cancer }\end{array}$} & \multirow{6}{*}{$\begin{array}{l}\text { Couch, Penn II, Myriad, Tyrer-Cuzick, } \\
\text { BRCAPRO, BOADICEA }\end{array}$} & BRCA1 & Breast cancer (age <45, two primaries, male) \\
\hline & & BRCA2 & Ovarian cancer \\
\hline & & & Pancreatic cancer \\
\hline & & & Prostate cancer \\
\hline & & & Ashkenazi ancestry \\
\hline & & & Family history (one side) \\
\hline \multirow[t]{4}{*}{ Lynch } & \multirow{4}{*}{$\begin{array}{l}\text { Wijnen, MMRpro, MMRPredict, } \\
\text { PREMM1,2,6 }\end{array}$} & MLH1 & Amsterdam I and II \\
\hline & & $\mathrm{MSH} 2$ & Bethesda (revised) \\
\hline & & MSH6 & Colorectal cancer \\
\hline & & & Endometrial cancer \\
\hline \multirow{3}{*}{$\begin{array}{l}\text { Li-Fraumeni and } \\
\text { Li-Fraumeni like }\end{array}$} & \multirow[t]{3}{*}{ none } & none & Classic \\
\hline & & & Eeles \\
\hline & & & Chompret (revised) \\
\hline \multirow[t]{2}{*}{ Cowden } & \multirow[t]{2}{*}{ Cleveland clinic } & PTEN & International Cowden Consortium \\
\hline & & & $\begin{array}{l}\text { Thyroid, oral papillomas, acral keratoses, skin lipomas, } \\
\text { trichilemmomas, uterine leiomyomas, gastrointestinal } \\
\text { polyps, dysplastic cerebellar gangliocytoma, fibrocystic } \\
\text { breast disease }\end{array}$ \\
\hline Hereditary melanoma & MELApro & CDKN2A & Melanoma \\
\hline
\end{tabular}

*included in mutation probability models.

genetic screening for Lynch syndrome in the general population [25].

Nevertheless, several models may underestimate mutation probability in certain situations such as a limited family structure or specific tumor characteristics [26]. Thus, probabilities predicted by a model must be interpreted in the context of an individual's personal and family history. The National Comprehensive Cancer Network (NCCN) in USA publishes guidelines annually in order to help clinicians to select which patients are appropriate candidates for either genetic referral or genetic testing $[27,28]$.

\section{Predicting cancer risks}

In the absence of an identified gene mutation, counseling unaffected individuals about their empiric risk of cancer requires careful consideration of the patient's personal and family history.

Most risk estimates for cancer development are empirical, based on the probability of a genetic component in the individual, and this risk estimate increases if the proband has several affected relatives on the same side of family with the same or related cancers, multiple or early onset cancers, or if the individual has clinical features of a hereditary cancer syndrome [29].

For breast cancer, there are several models that estimate empiric risks, including the Gail [30], Claus [31], BRCAPRO [9-11], Tyrer-Cuzick [12] and BOADICEA
[13] models. All of these models incorporate firstdegree relatives with breast cancer along with hormone risk factors, although they may vary in which known breast cancer risk factors are incorporated. There are also some published tools available to assess risks for colon, ovarian, lung and melanoma, but few are validated [32]. However, for prostate cancer, whose familial risk is known to be associated with dozens of low-penetrant variants [33], there is not a genetic model so far. Predictability based on the number of affected relatives, degree of consanguinity and also ancestry could be calculated by mathematical models to estimate empiric risks and possibly guide recommendations for appropriate screening. The undergoing discovery of functional alleles reinforces the need for new models to incorporate them better address cancer risk assessment.

Moreover, because those models that convert genotypes into absolute risks are empirically derived, prospective research is needed to confirm the accuracy of these predictions and evaluate the effectiveness of interventions based on individual genetic testing. For instance, the National Institute for Health and Care Excellence (NICE) in the United Kingdom recently released guidelines concerning risk assessment and management of familial breast cancer, even when testing is not performed [34].

How should risks be communicated? They can be given as cancer risk per year, or before a certain age, or within a decade, or as an overall lifetime risk in comparison with 
the population risk in terms of relative risks. The individual perception of cancer risk should be assessed, as should its possible effects on the health and lifestyle behaviors.

\section{Pre-test counseling}

After establishing risks of identifying a pathogenic germline mutation in a family and indicating the best candidates to be tested, it follows the information process of pre-test genetic counseling, which requires informed consent for testing for a mutation in a cancer susceptibility gene (see list below). It explains the eventual limitations of testing, its possible results, the emotional impact that may arise, and its relevance for employment and insurance. This approach must be nondirective, letting patients make their own decisions after knowing all possible scenarios [35]. In some circumstances, a pathogenic mutation will not be identified but genetic variants with unknown clinical significance, requiring further testing and reclassification. When a known deleterious mutation is detected in a family member, and when the affected individual agrees to release his/her results to the family, predictive testing can be offered to at-risk relatives. Predictive testing often requires two pre-test counseling interviews with up to three months between them, when family, emotional, employment and insurance issues are discussed, as well inheritance and penetrance of the mutation are explained. Screening and preventive options should also be discussed and it must be stressed that no surveillance guideline is flawless, so individuals must bear in mind that abnormal symptoms should never be ignored between screening exams [36].

\section{Basic elements of informed consent for testing cancer susceptibility genes}

1. information on the specific mutation(s) being tested, including whether the range of risk associated with the variant will impact medical care;

2. implications of a positive and negative result;

3. possibility that the test will not be informative;

4. options for risk estimation without genetic testing;

5. risk of passing a genetic variant to children;

6. technical accuracy of the test including where required by law, licensure of the laboratory;

7. fees involved in testing and counselling;

8. psychological implications of test results (benefits and risks);

9. risks and protections against genetic discrimination by employers or insurers;

10.confidentiality issues, including policies related to privacy and data security;

11.possible use of DNA testing samples in future research;

12.options and limitations of medical surveillance and strategies for prevention after genetic testing; 13.importance of sharing genetic test results with atrisk relatives so that they may benefit from this information;

14.plans for follow-up after testing.

\section{Post-test counseling}

When an affected or unaffected patient chooses to undergo testing, post-test counseling helps individuals to interpret and understand their results, whether positive, negative, undetermined or inconclusive. Psychological support may be provided as ambiguity and uncertainty may arise [35]. For example, individuals with a low-risk result may suffer from "the survivor guilt". High-risk individuals may need to explain positive results to their at-risk closest relatives and counselors (or geneticists) can help sharing this information. It should be emphasized that individuals who have had cancer may be psychologically affected and feel guilty by knowing their pathogenic germline mutation may be passed on through their offspring. In addition, since early diagnosis of cancer improves outcome, a clear protocol for surveillance and possible prophylactic measures must be offered to those at greater risks, even if they refuse or could not afford genetic testing. For example, riskreducing bilateral mastectomy when treating unilateral breast cancer in a BRCA1/BRCA2 mutation carrier or hysterectomy and bilateral salpingo-ooforectomy in a MSH6 mutation carrier. However, the application of such a system requires robust audit of outcomes, both related to cancer morbidity and mortality, and of psychological effects. Establishing a threshold level of risk at which to offer screening is needed in order to assess outcome. Those at moderately increased risk must engage in surveillance strategies whose specificity, sensitivity and cost-effectiveness should be addressed in the long term [36].

\section{Clinical sequencing}

Very recently, the American College of Medical Genetics and Genomics (ACMG) published a policy statement on recommendations for reporting incidental findings-those not related to the primary indication for testing but with potential medical utility-in clinical exome and genome sequencing. This working group presented a "minimum list" of Mendelian disorders for which any known pathogenic and expected pathogenic secondary variants would be routinely reported to the clinician who ordered clinical sequencing. The ACMG estimated that about $1 \%$ of sequencing results would include an incidental finding from this list. Remarkably, 16 of 24 disorders (67\%) are hereditary cancer syndromes and 13/16 (81\%) may be manifested during childhood. As recommended, these variants would be reported independently from patients' preferences and age, and the ordering physician would be 
responsible for providing patients and family members with pre-, post test counseling and follow up. The informed consent guidelines for this clinical context are expected to be released soon [37].

\section{Conclusions}

In summary, HCRA is an information process of estimating probabilities of germline mutations in cancer susceptibility genes and assessing empiric risks of cancer based on personal and family history in order to offer molecular diagnosis and clinical management. Providing patients with pre-and post-test genetic counseling can help them to achieve a better informed decision making. Following individuals at high risk with surveillance protocols (such as from NCCN and NICE), reassuring those at low risk, and referring those at increased risk of a hereditary cancer (whether carriers of primary or secondary variants) to a cancer genetics center with multidisciplinary outpatient clinics may allow the best suitable approach of HCRA. Specialized nurses can be settled in district hospitals to undertake pedigrees and risk assessment so they can refer individuals at moderately increased risk for surveillance, those at highly increased risk to the local cancer genetics center and reassure those at low risk.

In Brazil, a National Familial Cancer Network has been built in order to provide families with hereditary cancer a prompt access to diagnosis, management and counseling of the most common hereditary cancer syndromes in a public health care setting [38].

Collaboration with associations of patients and nongovernmental foundations would be extremely helpful to provide families with a better support and care.

\section{Competing interests}

The authors declare that they have no competing interests.

\section{Authors' contributions}

IG designed and wrote the manuscript. MPED supervised the manuscript. Both authors read and approved the final manuscript.

Received: 26 June 2013 Accepted: 21 October 2013

Published: 28 October 2013

\section{References}

1. Stadler ZK, Tom P, Robson ME, Weitzel JN, Kauff ND, Hurley KE, Devlin V, Gold B, Klein RJ, Offit K: Genome-wide association studies of cancer. J Clin Oncol 2010, 28:4255-4267.

2. Robson ME, Storm CD, Weitzel J, Wollins DS, Offit K: American society of clinical oncology policy statement update: genetic and genomic testing for cancer susceptibility. J Clin Oncol 2010, 28:893-901.

3. Trepanier A, Ahrens M, McKinnon W, Peters J, Stopfer J, Grumet SC, Manley S, Culver JO, Acton R, Larsen-Haidle J, Correia LA, Bennett R, Pettersen B, Ferlita TD, Costalas JW, Hunt K, Donlon S, Skrzynia C, Farrell C, Callif-Daley F, Vockley CW: Genetic cancer risk assessment and counseling: recommendations of the National society of genetic counselors. J Genet Couns 2004, 13:83-114.

4. Oncology Nursing Society: Role of the oncology nurse in cancer genetic counseling. http://www.ons.org.

5. Weitzel JN, Blazer KR, Mac Donald DJ, Culver OJ, Offit K: Genetics, genomics and risk assessment: state of the art and future directions in the era of personalized medicine. CA Cancer J Clin 2011, 61:327-359.
6. Couch F, DeShano ML, Blackwood MA, Calzone K, Stopfer J, Campeau L, Ganguly A, Rebbeck T, Weber BL: BRCA1 mutations in women attending clinics that evaluate the risk of breast cancer. N Engl J Med 1997, 336:1409-1415.

7. Lindor NM, Johnson KJ, Harvey H, Shane Pankratz V, Domchek SM, Hunt K, Wilson M, Cathie Smith M, Couch F: Predicting BRCA1 and BRCA2 gene mutationcarriers: comparison of PENN II model to previous study. Fam Cancer 2010, 9:495-502.

8. Frank TS, Deffenbaugh AM, Reid JE, Hulick M, Ward BE, Lingenfelter B, Gumpper KL, Scholl T, Tavtigian SV, Pruss DR, Critchfield GC: Clinical characteristics of individuals with germline mutations in BRCA1 and BRCA2: analysis of 10,000 individuals. J Clin Oncol 2002, 20:1480-1490.

9. Berry DA, Iversen ES Jr, Gudbjartsson DF, Hiller EH, Garber JE, Peshkin BN, Lerman C, Watson P, Lynch HT, Hilsenbeck SG, Rubinstein WS, Hughes KS, Parmigiani G: BRCAPRO validation, sensitivity of genetic testing of BRCA1/BRCA2, and prevalence of other breast cancer susceptibility genes. J Clin Oncol 2002, 20:2701-2712.

10. Berry DA, Parmigiani G, Sanchez J, Schildkraut J, Winer E: Probability of carrying a mutation of breast-ovarian cancer gene BRCA1 based on family history. J Natl Cancer Inst 1997, 89:227-238.

11. Parmigiani $G$, Berry $D$, Aguilar $O$ : Determining carrier probabilities for breast cancer-susceptibility genes BRCA1 and BRCA2. Am J Hum Genet 1998, 62:145-158.

12. Tyrer J, Duffy SW, Cuzick J: A breast cancer prediction model incorporating familial and personal risk factors. Stat Med 2004, 23:1111-1130.

13. Antoniou AC, Pharoah PP, Smith P, Easton DF: The BOADICEA model of genetic susceptibility to breast and ovarian cancer. Br J Cancer 2004, 91:1580-1590.

14. Wijnen JT, Vasen HFA, Khan PM, Zwinderman AH, van der Klift H, Mulder A Tops C, Møller P, Fodde R: Clinical findings with implications for genetic testing in families with clustering of colorectal cancer. N Engl J Med 1998, 339:511-518.

15. Chen S, Wang W, Lee S, Nafa K, Lee J, Romans K, Watson P, Gruber SB, Euhus D, Kinzler KW, Jass J, Gallinger S, Lindor NM, Casey G, Ellis N, Giardiello FM, Offit K, Parmigiani G: Colon cancer family registry: prediction of germline mutations and cancer risk in the Lynch syndrome. JAMA 2006, 296:1479-1487.

16. Barnetson RA, Tenesa A, Farrington SM, Nicholl ID, Cetnarskyj R, Porteous ME, Campbell H, Dunlop MG: Identification and survival of carriers of mutations in DNA mismatchrepair genes in colon cancer. $N$ Engl J Med 2006, 354:2751-2763.

17. Kastrinos F, Steyerberg EW, Mercado R, Balmaña J, Holter S, Gallinger S, Siegmund KD, Church JM, Jenkins MA, Lindor NM, Thibodeau SN, Burbidge LA, Wenstrup RJ, Syngal S: The PREMM $(1,2,6)$ model predicts risk of MLH1, $\mathrm{MSH} 2$, and MSH6 germline mutations based on cancer history. Gastroenterology 2011, 140:73-81.

18. Vasen HF, Watson P, Mecklin JP, Lynch HT: New clinical criteria for hereditary nonpolyposis colorectal cancer (HNPCC, Lynch syndrome) proposed by the International collaborative group on HNPCC. Gastroenterology 1999, 116:1453-1456.

19. Umar A, Boland CR, Terdiman JP, Syngal S, de la Chapelle A, Rüschoff J, Fishel R, Lindor NM, Burgart LJ, Hamelin R, Hamilton SR, Hiatt RA, Jass J, Lindblom A, Lynch HT, Peltomaki P, Ramsey SD, Rodriguez-Bigas MA, Vasen HF, Hawk ET, Barrett JC, Freedman AN, Srivastava S: Revised Bethesda guidelines for hereditary nonpolyposis colorectal cancer (Lynch syndrome) and microsatellite instability. J Natl Cancer Inst 2004, 96:261-268.

20. Li PP, Fraumeni JF: Soft tissue sarcomas, breast cancer and other neoplasms: a familial syndrome? Ann Int Med 1969, 71:747-752.

21. Chompret A, Brugieres L, Ronsin M, Gardes M, Dessarps-Freichey F, Abel A, Hua D, Ligot L, Dondon MG, Bressac-de Paillerets B, Frébourg T, Lemerle J, Bonaïti-Pellié C, Feunteun J: P53 germline mutations in childhood cancers and cancer risk for carrier individuals. Br J Cancer 2000, 82:1932-1937.

22. Eng C: Will the real Cowden syndrome please stand up: revised diagnostic criteria. J Med Genet 2000, 37:828-830.

23. Tan MH, Mester J, Peterson C, Yang Y, Chen JL, Rybicki LA, Milas K, Pederson $H$, Remzi B, Orloff MS, Eng C: A clinical scoring system for selection of patients for PTEN mutation testing is proposed on the basis of a prospective study of 3042 probands. Am J Hum Genet 2011, 88:42-56. 
24. Wang W, Niendorf KB, Patel D, Blackford A, Marroni F, Sober AJ, Parmigiani $\mathrm{G}$, Tsao H: Estimating CDKN2A carrier probability and personalizing cancer risk assessments in hereditary melanoma using MelaPRO. Cancer Res 2010, 70:552-559.

25. Dinh TA, Rosner Bl, Atwood JC, Boland CR, Syngal S, Vasen HF, Gruber SB, Burt RW: Health benefits and cost-effectiveness of primary genetic screening for Lynch syndrome in the general population. Cancer Prev Res (Phila) 2011, 4:9-22.

26. Kwon JS, Gutierrez-Barrera AM, Young D, Sun CC, Daniels MS, Lu KH, Arun B: Expanding the criteria for BRCA mutation testing in breast cancer survivors. J Clin Oncol 2010, 28:4214-4220.

27. National Comprehensive Cancer Network: NCCN practice guidelines V.1.2013: genetic/familial high-risk assessment: breast and ovarian. Fort Washington, PA: National Comprehensive Cancer Network; 2013. http://www.nccn.org.

28. National Comprehensive Cancer Network: NCCN practice guidelines V.2.2012: colorectal cancer screening. Fort Washington, PA: National Comprehensive Cancer Network; 2012. http://www.ncen.org.

29. Hampel H, Sweet K, Westman JA, Offit K, Eng C: Referral for cancer genetics consultation: a review and compilation of risk assessment criteria. J Med Genet 2004, 41:81-91.

30. Gail MH, Brinton LA, Byar DP, Corle DK, Green SB, Schairer C, Mulvihill Jj: Projecting individualized probabilities of developing breast cancer for white females who are being examined annually. J Natl Cancer Inst 1989, 81:1879-1886.

31. Claus EB, Risch N, Thompson WD: Autosomal dominant inheritance of earlyonset breast cancer: implications for risk prediction. Cancer 1994, 73:643-651.

32. National Cancer Institute (NCl): Risk factor monitoring and methods. http://appliedresearch.cancer.gov/about/ffmmb/research.html.

33. Fletcher O, Houlston RS: Architecture of inherited susceptibility to common cancer. Nature Rev Cancer 2010, 10:353-361.

34. National Institute for Health and Care Excellence (NICE): Classification and care of people at risk of familial breast cancer and management of breast cancer and related risks in people with a family history of breast cancer. http://guidance.nice.org.uk/cg164.

35. Garber J, Zon R, Weitzel J: Genetic counseling: an indispensable step in the genetic testing process. J Oncol Pract 2008, 4(2):96-98.

36. Hodgson SV, Foulkes WD, Eng C, Maher ER: A practical guide to human cancer genetics. 3rd edition. Cambridge, UK: Cambridge University Press; 2007.

37. Green RC, Berg JS, Grody WW, Kalia SS, Korf BR, Martin CL, McGuire AL, Nussbaum RL, O'Daniel JM, Ormond KE, Rehm HL, Watson MS, Williams MS, Biesecker LG: ACMG recommendations for reporting of incidental findings in clinical exome and genome sequencing. Genet Med 2013, 15(7):565-574.

38. Ministério da Saúde. Instituto Nacional de Câncer (INCA): Rede nacional de câncer familial: manual operacional. Rio de Janeiro, Brazil: Coordenação de Educação (CEDC); 2009.

doi:10.1186/1897-4287-11-16

Cite this article as: Gomy and Estevez Diz: Hereditary cancer risk assessment: essential tools for a better approach. Hereditary Cancer in Clinical Practice 2013 11:16.

\section{Submit your next manuscript to BioMed Central and take full advantage of:}

- Convenient online submission

- Thorough peer review

- No space constraints or color figure charges

- Immediate publication on acceptance

- Inclusion in PubMed, CAS, Scopus and Google Scholar

- Research which is freely available for redistribution 